"Vox Patrum" 6/1986/z. 11

\title{
ZAPROSZENIE ŚW. AUGUSTYNA NA SOBÓR EFESKI*
}

Bibliografia rejestrujzca publikacje augustyńskie od 1950 roku, zebrana przez 0. T. Van Bavela 1 C. Andresena ${ }^{2}$, jak równiez biezaca, ogłaszana $w$ "Revue des Etudes Augustiniennes", nie odnotowuje nowszej pozycj1 ${ }^{3}$ dotyczacej wymienionego wytule tematu, n1z opublikowany $w 1952 \mathrm{r}^{4}{ }^{4}$ portórzony $1967 \mathrm{r}^{5}$ zajmujący s1e rónniez tym zagadnieniem artykuł B. Altanera pt. "Augustinus in der griechischen Kirche b1s auf photius". Z powodu braku źródeł równiez 1 dzisiaj niewiele moźna dorzucić do wywodów Altanera. Warto jednak zwrócić uwage na kontakty Biskupa Hippony z Janem Jerozolimskim, Cyrylem - najprawdopodobniej biskupem aleksandryjskim, 1 z Attykiem - biskupem konstantynopolitańskim na podstawie odkrytych w 1975 r. 1 opublikowanych w 1981 r. nleznanych dotąd jego listón do kymientonych adresatów. Przy rozwlązywaniu postawionego zagadnienia przedstawimy najpierw materiał źródłowy dotyczłcy pośmiertnego wyrózintenta św. Augustyna.

Zaraz na wstęple trzeba przypomnieć, ze nie zachował sie nam sam tekst pisma cesarskiego zapraszającego biskupa Hippony na Sobór

* Artykuł jest poprawiona wers ja odczytu wygłoszonego 14 mrześnia $1981 \mathrm{r}$. podczas sympozjum patrystyczno dogmatycznego w Niepokalanowie.

1 Réperto1re b1bliographique de St. Augustin 1950-1960, Steenbrug1s 1963.

2 Bibliographia Augustiniana, Darmstadt 1973.

3 W dawniejszej literaturze naukowej napotykamy interesujz̨co ujętą wzmlankę o zaproszeniu św. Augustyna na Sobór w Efezle w: C. J. Hefele-Leclercq, Histolre des Conciles, II 1, Paris 1908, 289. Ujęcie to warto porównać z nowszymi wzmiankauni na ten temat: P. Th. Camel ot, Ephese et Chalcédolne, Paris 1962, 46; A. Crabbe, The Invitation List to the Council of Ephesus and Metropolitan Hi erarchy in the Fifth Century, JTS 32/1981/ 369-400.

4 "H1stor1sches Jahrbuch" 71/1952/ 37-76.

5 B. Altaner, Klelne patristische Schriften, hrsg. G. Glockmann, Berl1n 1967, 57-98, o zaproszen1u św. Augustyna, 67-71. 
Efesk1. Zdanı jesteśmy tylko na relacje będące echem listu Teodozjusza II. Najwazniejsza jest tu wzmianka nastepcy Aureliusza, biskupa Kartaginy Kapreoiusa, zawarta w jego liście do uczestników Soboru Efeskiego. Kapreolus napisał ów list po Wielkanocy, która w 431 r. przypadła na dzień $19 \mathrm{kwietnia}{ }^{6}$. W piśmie tym Kapreolus donosi: "Dotarł do naszych rak list Pana 1 Syna naszego pobożnego cesarza Teodozjusza". Zawierał on "szczególne zadanie, by śp. brat 1 współbiskup nasz Augustyn był obecny na Soborze. List ten nie mógł go [Augustyna z zastać juz zywym /.../ Był on, jak siq zdaje, skierorany do wyzej wymienionego Augustyna ${ }^{7}$. Z cytowanego wyjątku listu Kapreolusa do Ojców Soboru Efeskiego dowiadujemy sie więc, ze Augustyn otrzymał cesarskie wezwanie, by wziac wim udział.

6 Por. Epistola ad Concilium Ephesinum I 1, PL 53, 845; Mans1 IV 1207; ACO I 2, s.64: "Imperiales in diebus Paschae ad nos venerunt litteras", przekład grecki: ACO I 1, 2, S.53; na marginesie E. Schmartz podal date "d. $19 \mathrm{~m}$. Apr. a. 431". Według reqopisu J. Sirmonda/PL 53, 845/ tekst ten brzmi nastąpująco: "Litteras Imperatoris in diebus paschae ad nos perlatas esse". List do synodu został, naszym zdaniem, wysłany przez Kapreolusa po świętach wielkanocnych, Jak to czytamy walszym ciagu tego listu: "Quando vix ad venerabilem totam synodum duorum mensium spatium restabat /.../ licet legatos nullo modo destinare potuimus propter reverentiam tamen debitam ecclesiasticae disciplinae filium meum Bessulam diaconum destinavimus" /ACO I 2, s. 64/. Końcówka 1 rozdz. listu Kapreolusa y tekście J. Sirmonda brzmi: "Una cum his excusationis litteris ad vos, venerabiles fratres, destinaverimus" /PL $53,845 \%$.

Epistola ad Concilium Ephesinum

\section{ACO I 2, s. 64:}

"Primum etenim domini et Pili1 nostri religiosissimi imperatoris Theodosil tales litterae ad manus nostras venerunt, quae beatae memoriae fratris et coepiscopi Augustini praesentiam specialiter exigebant, quae praedictae litterae in hac vita invenire eum nullatenus potuerunt. Unde ego qui ipsam imperialen notitiam, 11cet praedicto destinata videretur, accepi missan, et in omnibus provincils Africae competentibus litteris et solitis colloquils synodum

\section{PL 53, 845:}

Primum enim domint et rilli nostri religiosissimi Theodosii Imperatoris litterae ad manus nostras perlatae, eiusmodi erant, quae beatae memoriae eratris et coepiscopi nostri Augustini praesentiam peculiari ratione efflagitabant. Verum cum eae litterae 1llum $1 \mathrm{am}$ tum e vivis excessisse comperissent, ego regiam 1llam significationem, licet ad praedictum Augustinum praecipue destinata videretur, excipiens, missis ad universas Africae provincias congruis litteris consuestisque sermonibus, synodum cogere volui convenientem. 
Drugim chronologicznie źródłem wiadomości o zaproszentu Augustyna przez Teodozjusza II na Sobór Efeski jest, pochodzące z lat 560/566, cenne "Breviarium causae Nestorianorum et Eutychianorum" Liberatusa, archidiakont VI dzielnicy Kartaginy. Autor ten wzbogac1ł nasze wiadomości o Interesujacej sprawie informacją, ze Teodozjusz wysłał specjalnie wyzszego urzędnika/magisterianus/ imieniem Ewagniusz z osobistym zaproszeniem Augustyna na Sobór ${ }^{8}$.

Na tym kończa się posiadane teksty źródłowe odnoszące sie do samego urzędowego zaproszenia Augustyna przez Teodozjusza II na Sobór w Efezie. Ich znaczente zrozumiemy jednak lepiej, jezell wezmiemy do ręk1 list Teodozjusza II z 19 listopada 430 r. do Cyryla, biskupa Aleksandri1 ${ }^{9}$. pí́mie tym cesarz wzywa pod groźbą niełaski Bozej 1 cesarskiej Cyryla, aby sie udał do Efezu na dzień Piéćdziesiątnicy, zabierając ze sobą "niektórych poboznych biskupów ze swej prowincji, których uzna za wybitniejszych. Podobnie piszemy do wszystk1ch metropolitów ${ }^{10}$. Wynika z tego, ze cesarz jedynie dla Augustyna zrobił wyjątek, jezeli chodzi o przedstawicieli Kościoła zachodniego, 1 to ze względu na jego znakomitość teologiczną, a nie $z$ powodu stanowiska hierarchicznego 11 .

volu1 congregaren

Tekst greck1 znajduje s1e ACO I 1, 2, 8. 52, lub PL 53, 846.

8 Breviarium causae Nestorianorum et Eutychianorum 5, PL 68, 977, ACO I 2, 5, s.103: "Scripsit imperator sacram et beato Augustino Hipponiregensi episcopo per Evagnium magistrianum, ut ipse concilio praestaret sui praesentiam; qui Evagnius veniens Carthaginem magnam, audivit a Capreolo, ipsius urbis antistite beatum Augustinum ex hoc mundo migrasse ad Dominum, acceptisque ab eo ad imperatorem iltteris loquentibus de obitu beati Augustini, Constantinopolim, unde venerat, redi1t".

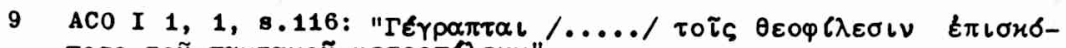

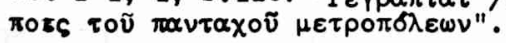

10 Poza metropolitami cesarz zaprosił jeszcze z Kościoła Wschodniego Szymona Słupnika. Por. ACO I 1, 1, s.112, w.22.

11 Por. B. Altaner, Augustinus in der griechischen Kirohe, art.cyt., 68. Jeszcze wipcu $431 \mathrm{r}$. /wedkug Hefele-Leclercq, Histoire des Conciles, dz: cyt., II $1,8.347 /$ lub w sierpniu $431 \mathrm{r}$. /wg A. Crabbe'a por: rec, L. Brixa, "levue des Etudes Augustiniennes" 28/1982/368/edykt cesarza Teodozjusza II deponujacy Cyryla z Aleksandri1, Memnona 1 Nestoriusza został przesłany takze do Augustyna, który od 11 miesięcy lub od roku juz nie zył. HefeleLeclercq tłumacza te przesyłke pomyłka kancelari1 cesarskiej /zob. wyzej/. A. Crabbe wyjánia ja raczej powtórzeniem listy zaproszonych biskupów z 19 listopada 430 r. przez kancelarię 
Nie możemy Jednak przemilczeć faktu, ze Teodozjusz II o wiele pó́niej nystosował list do Augustyna niz pismo do Cyryla Aleksandryjskiego 1 innych metropolitów, które nosi datę, Jak wspominaliśmy, 19 XI $430 \mathrm{roku}$. Moźna tu podzielać ubolewanie Altanera, ze nie wiemy, z czyjej Intcjatywy Teodozjusz II zaprosił Augustyna na Sobor ${ }^{12}$. Hefele 1 Leclercq oraz Altaner piszł, ze stało sił to ze względu na jego wielka sławę teologiczną ${ }^{13}$. Chodzi jednak o to, kto przypomniał cesarzowi, czy zwrócił jego uwagę na rozgłos, jakim c1eszył siz biskup fippony? Altaner z drugiej strony podkreśla, ze nie oznacza to bynajmniej jakiejś większej znajomości dzieł św. Augustyna na Wschodzle, bo greccy. teologowie nie znali w większośc1 Języka łacińskiego ${ }^{14}$. Mdmo to przypomina, ze Augustyn właśnie podczas sporu z pelagianami zwracal się dwukrotnie na Wschód do Jana, biskupa Jerozolimy ${ }^{15}$, którego w zaginionym liście prosił o nadestanie mu akt odbytego 20 grudnia $415 \mathrm{r}$. synodu w Diospolis, zwołanego w sprawie skargl złozonej na Pelagiusza ${ }^{16}$. Jan Jerozolimski, jak to wynika ze 179 listu Augustyna ${ }^{17}$, nie odpowiedział, co sį̨ niewątpliwie wiąze z jego dość życzliwym stosunkiem do Pelagiusza, a co znów z kolei znalazło swój wyraz na Konferencji Jerozolimskiej 445 roku $^{18}$. Na następne usilne prośby Augustyna, o których jest mowa we wspomnianym liście z 416 r., Jan przysłał

cesarską, niż ułożentem nowej listy biskupów obecnych na Soborze, bo wywołałaby ona spory co do pierwszeństwa.

12 Augustinus in der griechischen Kirche, art. cyt., 68.

13 Hefele-Leclercq, Histoire des Conciles, dz. cyt., II 1, s. 289: "à cause de sa grande célébrité".

14 Augustinus in der griechischen Kirche, art. cyt., 69.

15 Tamze, 70.

16 Epistola 179, 7 /Ad coepiscopum Joannem/, CSEL 44, 695: "Peto etiam nobis transmittere, quibus/Pelagius/ perhibetur esse purgatus, ecclesiastica gesta digneris".

17 Tamże, 1, CSEL 44, 691: "Quod tuae sanctitatis scripta non merui".

18 Tamże; "Pelagium vero fratrem nostrum, filium tuum, quem audio quod multum diligis"; por. G. de Plinval, Pelage, sesécrits, 8 a vie et sa reforme, Lausanne 1943, 277-278. 
Augustynow1 ów upragniony grecki protok6 $z$ z obrad synodu, wiedzi na co,biskup Hippony przekazał mu traktat Pelagiusza "De natura" oraz swoją na niego odpowiedź "De natura et gratian"19. I na tym urrały się kontakty między Augustynem 1 Janem. Mamy tu w każdym razie dowód nawiązania kqczności ze Wischodem w dziedzinie rozstrzygnięć synodalnych 1 dyskusji teologicznych.

Altaner wymienia równiez Cyryla z Aleksandri1, do którego pisal Augustyn. Zagadnienie to jednak jest dość skomplikowane, gdyz list ów zaginął, a ponadto wiadomość o nim jest pośrednia, 1 wreszcie, co najwazniejsze, przekaz o liście nie wymienia wprost Cyryla jako adresata. Dowiadujemy sie o nim tylko od Juliana $z$ Eklanu, który go wspomina w swej ksiązce "Ad Florum" przekazanej nam fragmentarycznie przez $\delta$. Augustyna w traktacie "Opus imperfectum contra Julianum". Interesujący nas fragment brzmi następująco: "De quo o p e $\mathrm{r}$ e Hieronym tu Augustine in illa epistola, quam Alexandriam destinasti, 1ta gloriaris, ut dicas Pelagium, Scripturarum ab eo oppressum molibus, arbittrium liberum vindicare non possen ${ }^{20}$. Wielu uczonych od starego Tillemonta poprzez Bardýego do Altanera ${ }^{21}$ wazcznie uważa, ze list skierowany do Kościoła w Aleksandril miał za adresata Cyryla będącego mómczas biskupem w tym mieście. Pogląd ten - zdaje sie mieć ostatnio poparcie w świezo dokonanym przez J. Divjaka odkryciu 2911 stów Augustyna /z wyJątkiem 11,który jest l1stem Konsencjusza do Augustyna 127 , będącym listem Hieronima do Aureliusza/22. Otó ${ }^{22}$ 118t 4 spośród nich kieruje Augustyn w $417 \mathrm{r}$. do pewnego Cyryla b1skupa 23 , którym według

19 Tamze, 5, CSEL 44, 694: "Quid/Pelagius/ in libro suo scripser1t, ignoratis. Propter hoc 1psum librum m1si et meum, quo ei respondi".

20 Opus imperfectum contra Julianum IV 88, PL 45, 1389.

21 L. de Tilemont, Memolres pour servir l'histoire ecclésiastique, XIII, Paris 1710,759 ; G. Bardy, S. Augustin l'homme et l'oeuvre, Paris 1940, 273; B. Altaner, Augustinus in der griechischen Kirche, art. cyt., 70.

22 CSEL 88,51 1 130; por. G. Madec, Du nouveau dans la correspondace augustinienne, "Revue des Études Augustiniennes" 27/1981/56-66.

23 J. Divjak, Introduct1o, CSEL 88, LV ; G. Madec, Du nouveau dans la correspondace augustinienne, art. cyt., 59, uścíśla tę datę: "au plus tôt". 
D1vjaka ma być biskup Aleksandri1. W p1śmie tym Augustyn przypomina, ze Cyryl przesłał nu akta synodu w Diospolis oraz Informuje, ze napisał "De gestis Pelagii" /416 r./24. Traktat ten jest najprawdopodobniej rówieśnikiera cytowanego wyżej 179 listu Augustyna 1 wspominanego drugiego listu do Jana Jerozolimskiego, co stanowi pewnego rodzaju trudność przy upatrywaniu w Cyrylu Aleksandryjskim adresata świeźo odkrytego listu. Augustyn prosił ponadto nie tylko Jana o akta synodu, ale Jak to wynika z "De gestis Pelagil" otrzymał je 1 skądinąd. Można na to odpowiedzieć, ze Augustyn, któremu bardzo zależało na posiadaniu tych akt, mógł stará́ siz̨ o nie 1 u Jana, 1 u Cyryla. Póńniej Jednak nie podtrzymywał kontaktu z Cyrylem prawdopodobnie dlatego, ze biskup aleksandryjski po potepieniu pelagianizmu przez Inocentego I w 417 r. nie wyłączył pelagian ze społecznośc1 Kościoła ${ }^{25}$. Mimo tego pelaglanizm nie uchodz1ł uwadze hierarchów Kościoła wschodniego, jak o tym świadczy wypędzenie ok. $416 \mathrm{r}$. przez patriarche konstantynopolitanskiego dttyka /406-425/ Celestiusza z Konstantynopola ${ }^{26}$. I znowu odnaleziony niedawno przez Divjaka list Augustyna do tegoz Attyka/1ist 6/ inPormuje nas o pewnych kontaktach Augustyna ze Wschodem. Z listu tego bowiem dowiadujemy się, ze Augustyn oczekiwał jakichś wiadomośo1 od Attyka, ale ten ich mu nie udzielił, bo na ischodzie krązyły juz pogłoski o śmierci biskupa Hippony: Co więcej, Augustyn $n$ tym l1ście rozprawia o małzeństwie 1 o pożądliwości w nim 1stniejłcej, rózniącej się jednak od pozamałżeńskich pożądliwośc1 zmysłonych $/ \mathrm{n}$. $5 /$. Sam zaś list kończy słowami: "Wybacz mi ucizżliwośc, jaka sprawił

24 Epistola 4, 2, CSEL 88, 26: "Recolit quantum arbitror sinceritas tua misisse te nobis gesta ecclesiastica habita in provincia Palestina, ubi Pelagius putatus catholicus absolutus est $/ \ldots /$ quibus gestis quantum diligenter potui consideratis atque perpetspectis librum de his ad venerabilem fratrem et consacerdotem nostrum Aurelium ecclesiae Carthaginensis episcopum scripsi".

25 Epistola Eusebil ad Cyrillum, CSEL 35, 114: "Quomodo nunc, cum beatae memoriae Innocentius haeresim Pelagianam Caelestianamque cum suis capitibus condemnaverit, cunctis eos abicientibus orientalibus Alexandrina sola ecclesia in communionem recepit".

26 Marius Mercator, Commonitorium super nomine Caelest11, ACo I 5, 1, s. 66: "Post aliquantos annos sub sanctae memoriae Attico episcopo urbem Constantinopolitanam petilt, ubi in similibus detectus, magno studio sancti lliius viri ex praedicta alma urbe detrusus est, litteris super eius nomine et in Asiam et Thessalonicam et Carthaginem ad episcopos missis, quarum exem- 
Twolm ǵniętym myślom mój rozwlekły l1st. Napisałem go nie po to, by ole jeszcze więcej pouczyć, lecz, aby wobec clebie odeprzeć oszczerstwa pelagian". Wazna jest data napisania tego listu, co do której niestety, nie mozemy dać pewnej odpowiedzi. Czas jego napisania waha sie bowiem redług niesprecyzowanej ${ }^{27}$ chronologil Divjaka między latami $416 / 417$ a $419 / z e$ wględu na list Hieronima, który dostarczono Augustynowi, według Al. Goldbachera właśnie w 419 roku/28. Divjak ponadto wskazuje na równoległe teksty występujące - znanym Juz na Wrchodzie traktacie "De nuptils et concupiscentia" nap1sanym w latach 419-420/2129. Czasokres więc napisania listu Augustyna do Attyka wydłuza się na lata 416-421.

Mamy Jeszcze inne dowody, ze dzieło Augustyna "De nupti1s et concupiscentia" znane było na Wschodzie, a czerpiemy je od wrogów biskupa Hippony: od Juliana z Eklanu $i$ od Florusa. I tak Julian z Elanu poświadcza istnienie II ksiegi "De nuptils et concupiscentian, "Konstantynopolu $421 \mathrm{r}$., kiedy to schroniwszy sie w Cylicji u Teodora z Mopsuesti1 ${ }^{30}$ otrzymał ja tam właśnie od swego przyjaciela Florusa II. Ten zachęcał Juliana, by odpowiedział na replikę Augustyna31. Julian, Jak zwykle, wyraża się nieścíśle 1 obelźywie

plaria habentes proferre sumus parati".

27 G. Madec, Du nouveau dans la correspondance augustinienne, art. oyt., 60 .

28 Por. Index III de epistularum $S$. Augustini ordine atque temporibus, CSEL 58, 52 .

29 Por. Bleuzen de Veer, Bibliographia Augustiniana, XXIII, 25.

30 Marius Mercator, Commonitorium adversum haeresim Pelagil 15, ACO I 5, 1, s. 23: "Iulianum ex episcopo oppidi Eclanensis, haereticum Pelagianum seu Caelestianum, hunc secutum esse Theodorum, ad quem peragratis terris et exarato mari atque oriente lustrato cum socils et particibus, sane syntaleporis suis magno nisu tamquam ad Christianorum dogmatum praedicatum magistrum tetendit, ut de haeresi Pelagiana seu Caelestiana, quam defendendan et sequendam suscepit, ab ipso confirmaretur atque inde velut instructior octo contra fidein catholicam potius quam contra sanctae memoriae Augustinum uolumina illa, ut putat, prudentissima conderet"; por. A. Bruckner, Julian von Eclanum, sein Leben und seine Lehre, Leipzig 1897, 46-48.

31 Opus imperfectum contra Julianum I 7, PL 45, 1153: "Id Impendio poposcisti, 1mmo indixisti/Flore/ auctoritate patria, ut libro tractatoris Poeni, quem ad Valerium comitem vernula peccatorum elus Alypius nuper detulit, obviarem". 
- traktacie Augustyna, nazywajac go "Manichei epistula Inventa est ${ }^{32}$. Bardziej jednak znaczące sa poprzedzajace słowa Juliana: "Apud Constantinopolim Manichae1 epistola Inventa est atque/ ad has directa partes" ${ }^{33}$. Z powyzszego wyn1ka, ze stosunkowo wcześnie po napisaniu, Jak na ówczesne warunk1 komunikacyjne, znalazł sie - Konstantynopolu traktat biskupa Hippony "De nuptiss et concupiscentia". Mimo więc trudności językowych 1 braku łączności między Augustynem a ojcami wschodnimi, co najmniej - jak widać - jedno antypelagiańskie dzieło Augustyna znane było w Konstantynopolu. Byzo ono oczywície znane przede wszystkim w środowisku łacińskim, moźna Jednak przypuszczać, ze pośrednio jego treść zakomunikowaz Augustyn biskupowi Konstantynopola Attykowi. Jezell chodzi o łacinników, to z pewnościa Julian, a być moze 1 Inni, dzielił się wiadomościami o przedmiocie swej polemiki z Augustynem. Tego rodzaju zaś, aczkolwiek dość skąpe 1 ograniczone wiadomości mogły wystarczyć, aby juz nie wrogi, ale jakiś zyczliwy informator zachęcıł co najmniej doradców cesarza, by się zainteresował biskupem dalekiej Hippony 1 zaprosil go do wzięcia udziału w Soborze Efeskim. Potepienie zaś pelagianizmu na tym Soborze 34 sprawiło, ze cały Kośció odrzucił zdecydowanie te błędy, co w sumie stanowiło posmiertne, ostateczne zwycięstwo Doktora łaski.

$$
\text { Ks. Wacław Eborowicz - Pelplin }
$$

\section{INVITATION DE ST AUGUSTIN AU CONCILE D'EPHeSE Mésuméf}

En présentant les détails nouveaux, l'auteur tient à compléter l articlede B. Altaner sur l invitation de St Augustin au Concile d'sphèse par 1 empereur Théodose II.

32 Tamże, III 166, PL 45, 1316.

33 Tauze.

34 Gesta Ephesena. Synodi epistula generalis 5, ACO I 1, 3, s.28:

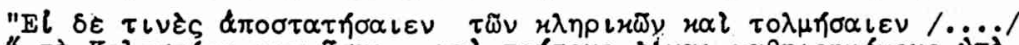

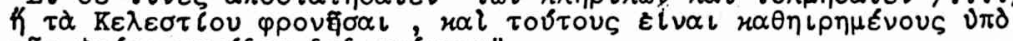

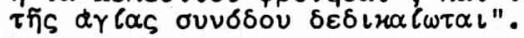

